\title{
The Enlightenment of the Financing Modes of European and American Charitable Organizations to China
}

\author{
Tenpao Lee ${ }^{1}$, \\ Niagara University \\ Zhongwei zhang ${ }^{3}$ \\ Jianghan University
}

\author{
Dong Liang ${ }^{2 *}$, \\ Jinmei $\mathrm{Lu}^{4}$ \\ Jianghan University
}

Business School, Jianghan University

\begin{abstract}
With the social and economic development, as a charitable organization, but not the government and for-profit organizations in helping disadvantaged groups to address poverty and other aspects are playing an increasingly important role. Financing is the supportive one and can be survived for current charities to achieve their goals. The survival and development of charities in our country undoubtedly need the support of funds. It is related to the healthy and sustained development of charities in our country. Compared with many countries in Europe and the United States, the development of China's charity organizations is not yet very mature, and the facilities are not yet perfect. Therefore, drawing lessons from the charity fund-raising patterns in Europe and the United States is of great significance to the rapid development of China's charities. This paper draws lessons from the financing model of charity organizations in Europe and the United States, analyzes the status quo and existing problems in the operation of charities in China, and puts forward the countermeasures of perfecting the financing model of charities in our country.
\end{abstract}

Keywords-Charitable organizations; Financing model; Continuous development; Countermeasures Analysis

\section{INTRODUCTION}

Charitable organizations are those not for profit, that the public service for the purpose of the public sector outside the government. It is generally believed that charitable organizations have four characteristics: First, organizational, that is, those who have a formal organizational process, organizational structure and management mechanism; the second is the relative independence of those agencies and national government agencies, as well as other for-profit Third, non-governmental means that the funds obtained by the organization can only be used for public service activities and cannot be used for activities such as dividends; Fourth, voluntary, that is, whether the organization is or not The principle of complete voluntariness has been adopted both in the establishment and in the membership of the organization. Due to their charitable benefits, flexibility, high social participation and strong communication and coordination, charitable organizations make them improve the quality and efficiency of public services, promote social fairness, meet the needs of diverse society and ease public financial pressure and other aspects played a huge role in promoting.

\section{FUND-RAISING MODELS FOR EUROPEAN AND AMERICAN CHARITABLE ORGANIZATIONS}

Funds abroad mainly include government subsidies, nongovernmental donations, service charges, issuance of lottery tickets and foreign aid. Due to the differences in cultures and customs between countries, the composition of funding sources of charities in various countries is also different from each other. Charities in various countries have certain dependency on the first three modes of financing, but the difference is that the financing of some charities in developing countries still depends on the foreign-funded model.

\section{A. Government subsidies}

Government subsidies, mainly divided into direct subsidies and indirect subsidies in two ways. There are direct subsidies direct subsidies, contracts and compensation in these three forms. Direct funding means that the government gives subsidies directly to charitable organizations to support their activities and projects. The contract shows that charities provide services to those who are eligible for certain government projects and the public agencies are responsible for paying service fees. The compensation is paid by the government Compensation will be paid to those who qualify for government projects and buy services from charities. In the United States, for example, government subsidies for charitable organizations are divided into direct and indirect forms of subsidy [1]. As early as 1980, the federal government directly funded charitable organizations as much as 41 billion U.S. dollars, accounting for $35 \%$ of charity's total revenue. In addition to direct funding, the federal government's indirect approach to philanthropic organizations includes a waiver of income tax on charitable organizations and a tax reduction on private and corporate non-profit contributions. In general, government subsidies and allocations in developed countries 
are the largest sources of funding for charities, but not in most developing countries.

\section{B. Private donations}

As a private donation that is different from the public sector and private-for-profit institutions, it is a unique source of income for charities. Its donations come mainly from individuals, foundations and enterprises. Among them, individual donation accounts for the largest proportion of the three. In the United States, for example, the Annual Philanthropy Report released last year by the U.S. Charity Foundation shows that charitable donations by U.S. individuals, inheritance, foundations and businesses in 2016 increased by almost $3 \%$ to 3.9005 billion in 2016 as compared with 2015 The U.S. dollar accounts for about $2.1 \%$ of the U.S. gross domestic product. Personal donation is the largest part of all donations, accounting for about $72 \%$ of total amount of charity donations in 2016, up to 282 billion US dollars. Foundation donations accounted for about $15 \%$ of the total donations, about 59.3 billion US dollars, an increase of $3.5 \%$ compared to last year. Corporate donations rose $3.5 \%$ to reach 18.6 billion U.S. dollars.

(Data

Sources

http://www.chinadevelopmentbrief.org.cn/news-19665.html):

\section{Issue lottery}

In Europe and America, charitable organizations to raise funds through the issue of the lottery are a very important way. Because charitable organizations do not have the ability to raise funds through tax regimes, "charitable gambling" may be an important way that current charities can legally receive funding. Some countries also conduct lottery operations for the purpose of charity and issue a series of decrees aimed at the issuance of lotteries to regulate lottery activities. For example, according to the relevant Brazilian legislation, the lottery activities are managed and operated uniformly by the Federal Savings Bank and the lottery is issued through the Federal Reserve Bank's Fund Raising Department and its branches in the states of the country. Its purpose is to provide education and sports, health care, Welfare to raise funds [2].

\section{Service charges}

Service charges, mainly includes charitable organizations dues, sales or service costs. One of the most important sources of funding for charitable organizations is dues income. Contributions are mainly charged to members of charitable organizations that provide public goods to restrain their clients and make members non-competitive with the consumption of public goods. In some western European countries, contributions have to surpass their total income in the public sector and become an important source of funding for charitable organizations. In Japan, for example, most of the country's charities do not come from charitable donations, but from service revenues and public sector support.

\section{E. Foreign aids}

Foreign aid refers to grants or donations given by charitable organizations from government agencies, foundations and other organizations in developed countries. This is mainly aimed at a large number of developing countries. Due to the impact of economic development and other factors, the government subsidies and contribution income enjoyed by some charities in developing countries still cannot maintain the normal operation of charities [3]. Charities cannot raise enough charity funds to carry out charitable activities. Foreign aid has become an important source of income for charities in developing countries.

\section{CURRENT SITUATIONS OF CHARITABLE ORGANIZATIONS IN CHINA}

\section{A. The status quo of charitable organizations in China}

In recent years, with the improvement of charity environment in our country, the donation enthusiasm of the public and enterprises has been unprecedentedly high, and the charity market in our country has shown a rapid development. 2016 is an important turning point in the history of charity in China. It is also a year in which the state and society are closely united to promote the development of charities. According to the data given in "Charity Blue Book: China Charity Development Report", in 2016, the total amount of funds in China's charity market reached 288.1 billion Yuan, of which 136.4 billion Yuan was donated to society. Compared with 2015 , the total social donation growth rate in 2016 was $10.5 \%$, accounting for $0.38 \%$ of the total national GDP in 2016 In the first half of 2017, the total amount of charity funds raised by our country has reached 158.4 billion Yuan. It can be said that the current stage of raising funds for charitable organizations in China is still mainly based on passive acceptance of donations. Donations for the regional classification criteria, financing can be divided into two forms of foreign and domestic sources of donations in China charitable organizations. Domestic donations can be divided into government subsidies, corporate donations, personal donations, lottery charity donations four. Overseas donations refer to the overseas donations received by the Mainland from overseas countries, international organizations, Hong Kong, Macao and Taiwan regions and overseas Chinese. In these channels, donations from Hong Kong, Macao and overseas Chinese are higher (Data Source: "Charity Blue Book: China Charity Development Report").

Since charitable organizations started relatively late in China, the mass foundation is relatively weak and the external supporting system is not yet fully developed. There are still many problems in its development. The autonomy and independence are not strong, the organization mobilization ability is not strong, the international influence is not big, the public participation insufficiency, the imperfect system construction and so on are all restricting the development of the charity in our country. A considerable part of China's charitable organizations are seriously underfunded and unable to carry out their activities normally. Many organizations are actually in a dormant state in name only [9]. 


\section{B. China's charity operation problems}

According to a survey conducted by Tsinghua University Institute of Charitable Organizations, more than $50 \%$ of China's charitable organizations' revenue comes from the government's financial subsidies and appropriations. $21.18 \%$ of the revenue comes from contribution income, and the average operating income is $6 \%$. The sponsors and project funds provided by the enterprises accounting for $5.63 \%$, the proportion of other income is less than $5 \%$. This fund shows that there are many irrational places in the structure of charities in our country. To the extent that the government is overly dependent, the proportion of operating income is low and the social credibility is low, it is an issue urgently needed to be solved by our country's charitable organizations.

\section{1) Charities are too dependent on the government}

The government's financial subsidies and appropriations are the most important sources of funds for charitable organizations, which objectively causes the charitable organizations in our country not to be independent in realizing their own organizational goals. To varying degrees, charitable organizations depend on the government departments. At the same time, the government must take the opportunity to intervene in charitable organizations, weaken the autonomy of the organization and constrain the vitality of the organization.

The dependence on government funds is the bottleneck of the development of charitable organizations in our country. Adhering to a diversified fund-raising strategy, increasing value-added assets and improving financial independence are the fundamental ways for charitable organizations to raise funds. Charities should actively create conditions for this. With the support and assistance of the government, they can increase the operating income of charitable organizations and obtain more funds. They can also open more markets and increase cooperation with enterprises funds [7].

\section{2) The proportion of operating income is too low}

Operating income, which is the service fee charged by charitable organizations for carrying out their business activities in order to realize their social mission. The low proportion of operating income in our country's charity organizations and the over-reliance on other sectors in terms of funding indicate that most of our charities are still stuck in "waiting, relying on, and wanting" on the government and lacking the operation of their own markets Initiative, lack of vitality of the organization's development, thus forming the bottleneck of its own development.

\section{3) Philanthropic social trust is low}

The level of social credibility relates to the public support for charitable organizations for charity activities, related to the amount of fund-raising income, thus affecting the completion of charitable organizations to raise funds. The current regulation of charities in our country is not too in place, the lack of a more effective system for regulatory oversight. The United States and other developed countries have formed a sound supervision and management of civil society organizations, policies and regulations, in daily operations, in addition to strict supervision and management of the government, charitable organizations must report detailed annual budget revenue and expenditure to US Internal Revenue Service each year, changes in assets and the use of various funds and assume the responsibility of publishing the financial status of donors on time. To improve social credibility can be said that our current charitable organizations have an urgent obligation. Only with a wide range of social recognition and support can the mission of charitable organizations be successfully completed [6].

\section{Analysis of the Causes of Existing Problems in China's Charitable Organizations}

1) Charity Organizational Mechanism of Inherent deficiencies and the day after tomorrow "weak"

Due to the non-profit characteristics of charities, it determines that the funds they raise can't be owned by individuals. This particularity causes charities to fail to form an effective profit-driven mechanism and responsibility supervision mechanism during the fund-raising process. As a result, charities Organizational deficiencies in the funding process. Funding mechanism for charitable organizations the day after tomorrow "weakness" is mainly reflected in the overreliance of the charitable organizations on the government in the fund-raising process. This is mainly caused by two reasons. The first is that the promotion of the government in the process of raising funds for charities is too important. The second is that some charities themselves are separated from the administrative system and are administratively colored. The existence of these two factors makes the charitable organizations in our country more difficult to raise funds.

\section{2) Legal and policy is not perfect, the lack of long-term} mechanism

Compared with the countries in Europe and the United States, the current tax exemption policy in our country is still not perfect. At present, only the two charities such as the Red Cross Society of China and China Charity Federation enjoy a completely tax-free policy. And our country has not promulgated the pertinence and the specific laws and regulations that regulate the charitable organization. There are still some shortages in the characterization of charitable organization, operation mechanism and supervision mechanism of charity. This has a very adverse impact on the smooth mobilization of charity companies and individuals. At present, most of our country's fund-raising organizations rely mainly on large-scale social mobilization for fund-raising, and have not established a long-term fund-raising mechanism that is timeefficient, geographically and emergent. This has caused the sudden charitable fund-raising in China's charitable organizations during the fund-raising process. However, institutionalized fundraising has been less, and the entire fundraising has a lack of a holistic view, which is detrimental to the long-term development of charities. 
3) Charitable organizations is of low credibility in the financing process

Credibility is the degree to which society accepts the trust of charities. The level of financing ability of charities is affected by the social credibility of charities. In general, the higher the credibility of the charitable organization, the stronger the ability to raise funds. Given that donors are willing to provide more material and financial resources, more trustworthy charities can get more donations and more project funding than less trustworthy charities, Charitable organizations to be more policy tilt. The main reason why the current charitable organizations in our country are not very credible in reality is caused by the following factors. First, the tendency of administration and bureaucratization has resulted in the restriction of the self-development capacity of charities. Second, after the charitable organizations raise funds, the performance of using the funds and their assessment are more difficult. Third, the media did not have enough information about charitable organizations and the self-discipline of some charities was weaker.

\section{REFLECTIONS ON THE FINANCING STRATEGIES OF CHARITABLE ORGANIZATIONS IN CHINA}

\section{A. To apply government funds, strengthen cooperation with the government}

As the main sponsor of current charitable organizations, the government should continue to increase its investment. On the one hand, this kind of input is reflected in the increase of capital injection. More importantly, it is given policy-oriented tilt and increased support for "soft input." This is mainly reflected in two aspects: One aspect is the motivation and policy support for the donation of individuals and enterprises through such channels as tax policy. Practice in various countries shows that tax policy is an effective way to encourage donations. In addition, charitable donations can be paid before tax, not included in the donor's taxable income. The Australian government provides $\$ 400$ million in indirect aid to charities in this form every year, effectively increasing the amount of donations for individuals and businesses [8]. At present, similar policies in China have only general provisions and lack the specific content that can make the policies workable. Relevant government agencies should attach importance to this issue and issue effective and operational laws and regulations as soon as possible to build a policy platform for enterprises and individuals to donate to charities. On the other hand, the government should also strengthen the supervision over the use of funds by charitable organizations. At present, many of China's donors and donors also lack the enthusiasm to donate due to concerns about their own use by non-governmental organizations. Therefore, the government should establish and improve a monitoring mechanism to prevent non-governmental organizations from wasting money and embezzling funds.

\section{B. Strengthen cooperation with enterprises to increase operating income}

Charitable organizations get funding through cooperation with enterprises, and through cooperation, enterprises can establish a good public image, get better product recognition, increase consumer brand loyalty and enhance employees' corporate culture identity, which means that public welfare marketing, Public service marketing refers to the establishment of cooperative relations with some third-party organizations (usually charitable organizations) by some enterprises in order to expand the public welfare activities of enterprises and continuously guide consumers to feel good about them and gradually establish consumer brand loyalty, To achieve the sustainable development of products. Some enterprises in Europe and the United States have gradually influenced their purchasing decisions by public relations through charity organizations or charitable organizations, public welfare activities as a carrier, or by themselves. In this respect, many organizations and enterprises in our country have made helpful attempts [4]. For example, Nongfu Spring cooperates with Hope Project, and every penny sold in Nongfushanquan has a penny donated to Hope Project, which has achieved good results. Facts have proved that charities and business cooperation can be said to complement each other, each taking the necessary to achieve win-win situation.

\section{To improve self-discipline mechanism to improve the credibility of charitable organizations}

Self-discipline mechanism is an important measure for charities to safeguard their own image and improve social credibility. Charities must exercise self-discipline and always pay attention to maintaining their own image in order to gain public trust and support. Increasing credibility is not only crucial to the financing of a charitable organization, but also directly related to the long-term development of charitable organizations. The credibility of charitable organizations is the extent to which society recognizes trust. It can be achieved through legal constraints and self-regulation [5].

At present, many charitable organizations have not done it transparent. Many charities in Europe and the United States publish their own financial reports on the Web to make people fully aware of their financial situation. Due to the late start of charity cause in our country, many charities have not yet announced their financial data on the website. Some even published the financial data, did not specify the exact whereabouts of each fund. If the financial flow can be further disclosed, detailed disclosure of the specific use of each income will have a positive effect on the social supervision and self-monitoring of the organization. 


\section{To provide quality of service to take the initiative to win public support}

The level of service capability is the key to the existence and development of charitable organizations. Charitable organizations have a wide range of social impact through effective services. They can transform the good reputation of an organization into intangible assets and gain the financial support from enterprises and the general public so as to enhance their capability. Organizational strength, improve the organization's service capabilities. We can constantly broaden the scope of services, innovate service forms, increase the attractiveness and cohesion of charitable organizations to the public, and gain the public's support through the improvement of the quality of service provided by charitable organizations.

\section{CONCLUSION AND OUTLOOK}

The financing mode of charitable organizations in Europe and the United States is mainly through government funding, acceptance of donations, the organization of amateur revenue and expenditure and through cooperation with enterprises engaged in public welfare marketing and other means, it is worth mentioning that the United States and Europe through public welfare marketing get funding, Taobao, a subsidiary of Alibaba in China, started this model of public welfare marketing last year. However, due to starttoo late, china's public service marketing is not mature enough and perfect. Public service marketing is a win-win process for charities and businesses. According to the research, under the premise of the same product quality, consumers are more inclined to choose products with philanthropic meaning, thus affecting consumers' brand loyalty and enhancing the market competitiveness of enterprises. In the meantime, charitable organizations have also raised the funds they need. In the financing models of these charities in Europe and the United States, how our government combines the conditions of our country with the development trend of the times to create new funding models and learn from it is an urgent issue for our charities.

Adhered to a diversified funding strategy, increasing valueadded assets, and improving their financial independence is the fundamental way for charitable organizations to raise funds. Charities should actively create conditions for this. At the same time, state-related laws should also provide charitable organizations with a space conducive to asset investment and industrialization. It is necessary to actively develop the charity culture, cultivate public awareness of charity and guide the public to form the correct concept of wealth and values and provide the charity with a broader resource base.

\section{ACKNOWLEDGMENT}

Fund: WZ2017Y10, 2017 open fund of Manufacturing Industry Development Research Center on Wuhan City Circle, Jianghan University

The Authors introduce:

Tenpao Lee1: 1954- Professor of Economics, Niagara University, USA, mainly engaged in the study of statistics and government economics.

DongLiang2: 1960 - professor at Jianghan University, Business School, is mainly engaged in the research of enterprise strategy and government strategy.

Zhongwei zhang3: 1994-Jianghan University Graduate School of Business, the main research direction for marketing and service engineering.

Jinmei Lu4: 1994-Jianghan University graduate student, the main research direction for the international cultural development strategy.

Corresponding Author: DongLiang2 Zhongwei Zhang3.

\section{REFERENCES}

[1] Xiangyu Tao, Wei-ming Peng. Enlightenment and Reference of China's Charity Fundraising Model to China [J] .Reform \& 2017 2017, (21) 6667. (In Chinese)

[2] Jizhen Li. American Philanthropic Research [D]. Shandong University, 2017. (In Chinese)

[3] Qi Wang. Analysis of the business model of charitable organizations [J]. Chinese and Foreign Entrepreneurs, 2015, (25): 176-177. (In Chinese)

[4] Hongbo Li. Marketing of American public charities and its revelation to China [D]. Nankai University, 2014. (In Chinese)

[5] Gan Pan, Kuijie Yin. British charity regulatory law system and its reference [J]. Administrative Forum, 2014, 21 (01): 96-100. (In Chinese)

[6] Min Wen. On the Deficiency and Reconstruction of the Credibility of China's Charitable Organizations [J]. Journal of Northwest University of Science and Technology, 2013, 33 (03): 5-7 + 52. (In Chinese)

[7] Hao Wu. China charity organization analysis and development road [D] .Zhejiang University, 2013. (In Chinese)

[8] Zixuan Liu. China's charity's main problems, roots and development strategies [D]. Northeast Normal University, 2012. (In Chinese)

[9] Wei Wang. Comparison of Governmental Management Models for Charitable Organizations between China and the United States [D]. Minzu University of China, 2012. (In Chinese) 